\title{
The origins of lumbosacral spinal evoked potentials in humans using a surface electrode recording technique
}

\author{
C YIANNIKAS, ${ }^{*}$ B T SHAHANI \\ From the Laboratory of Clinical Neurophysiology, Department of Neurology, Harvard Medical School and \\ Massachusetts General Hospital, Boston, Massachusetts, USA
}

SUMMARY Somatosensory evoked potentials were recorded over the lumbar spine and scalp in 12 normal subjects after stimulating the posterior tibial nerve at the knee and ankle and the sural nerve at the ankle. The H-reflex from the soleus muscle was recorded at the same time. The effects of stimulus intensity, frequency of stimulation and vibration were assessed. It was concluded that when the posterior tibial nerve was stimulated in the popliteal fossa, three negative peaks were recorded over the lumbosacral area. They arose from activity in the dorsal roots, the dorsal horn of the spinal cord (SD) and the ventral roots. In contrast when the posterior tibial nerve and the sural nerve were stimulated at the ankle only two negative peaks were recorded, a dorsal root potential and a spinal cord dorsum potential. In addition the data suggested that the peripheral nerve fibres that are involved with generating the surface recorded spinal potential with mixed nerve stimulation are primarily muscle afferents.

Responses recorded from the lumbosacral area may provide reliable and direct means of studying nerve conduction in proximal nerve and spinal roots: however, their clinical application and interpretation requires understanding their generation. Magladery et $a l^{1}$ recorded action potentials from the human thoracolumbar subdural space evoked by tibial nerve stimulation. In addition to propagated nerve action potentials from dorsal as well as ventral roots, they described a biphasic wave recorded over the dorsum of the spinal cord. More recently, relationships between spinal potentials, the H-reflex and direct motor responses of triceps surae were studied using surface recording techniques. Delbeke et $a l^{2}$ and Ratto $e t \mathrm{al}^{3}$ claimed that the first negative deflection over the caudal lumbosacral region was generated by afferent impulses in the dorsal roots, while the second negative peak was travelling in the opposite direction and generated by a reflexly elicited volley in the ventral roots. Other authors (Dimitrijevic et al, ${ }^{4}$. ElNegamy and Sedgwick ${ }^{5}$ and Phillips and Daube have suggested that while the first negative peak is travelling rostrally and is most likely a dorsal root afferent volley, the latency of the second peak is

\footnotetext{
*Present address, and address for reprint requests: Department of Neurophysiology, Westmead Hospital, Sydney, NSW, Australia.
}

Received 3 April 1987 and in revised form 10 October 1987. Accepted 26 October 1987 constant and may be volume conducted spinal cord activity. The inability of the latter studies to record a ventral root potential was not satisfactorily explained.

The aim of this study was to clarify these issues by studying the effects of high frequency stimulation and vibration on the spinal potentials evoked by stimulation of the posterior tibial nerve in the popliteal fossa and to demonstrate a relationship between them and the H-reflex. In addition, these are differentiated from the potentials obtained from mixed nerves (posterior tibial at the ankle) and cutaneous nerves (sural) that are not normally associated with the monosynaptic reflex. SEPS with stimulation of these nerves were also recorded from the scalp to assess the relative contribution of cutaneous muscle afferents to the spinal evoked response. The present study utilised single nerve stimulation to avoid the problems of synchronisation of the afferent and efferent volleys introduced when both legs are stimulated simultaneously and also deliberately used non-invasive techniques.

\section{Subjects and methods}

Experiments were conducted on 12 healthy volunteers aged 24 to 30 years: some were examined on several occasions. Measurements were made with the patient prone on a bed with a pillow placed under the abdomen to aid relaxation of the paraspinal muscles and with feet hanging over the end of 
the bed. They were asked to relax completely and go to sleep if possible.

Recording Recording electrodes were $9 \mathrm{~mm}$ gold discs placed between the spinous processes at T12, L1, L3, L5, S1. In some experiments only two recording sites were used $(\mathrm{Ll}$, L5). In all cases the reference electrode was placed over the contralateral bony prominence of the anterior superior iliac spine (Ic). In addition, in six of the subjects spinal (L1-Iliac crest, L3-L1) and scalp recordings $(\mathrm{Fz}-\mathrm{Cz}$; $\mathrm{Ci}$-Contralateral cortex; H-Cz; H-Ipsilateral cortex; $\mathrm{H}-\mathrm{Fz} ; \mathrm{H}-\mathrm{Cc}$ ) were made following stimulation of the posterior tibial and sural nerves at the ankle. Signals were amplified 200,000 times using the convention of $\mathrm{G} 2$ negative potential upward deflection via a DISA sensory amplifier with a bandpass of $20-2,000 \mathrm{~Hz}$ for spinal potentials and $2-2,000 \mathrm{~Hz}$ for scalp recordings. A ground strap was placed at mid-thigh level of the appropriate limb. Similar electrodes were placed over the triceps surae muscle (abductor hallucis in the case of the tibial nerve at the ankle) to monitor the reflex electrical activity. These signals were amplified using a DISA model EMG amplifier with a band width of 5-2,000 Hz. A TECA constant voltage isolated nerve stimulator was used. For posterior tibial nerve stimulation and $\mathrm{H}$-reflex recording, the stimulus pulse had a duration of $0.7 \mathrm{~ms}$ and was presented at a rate of $0.5 \mathrm{~Hz}$. In

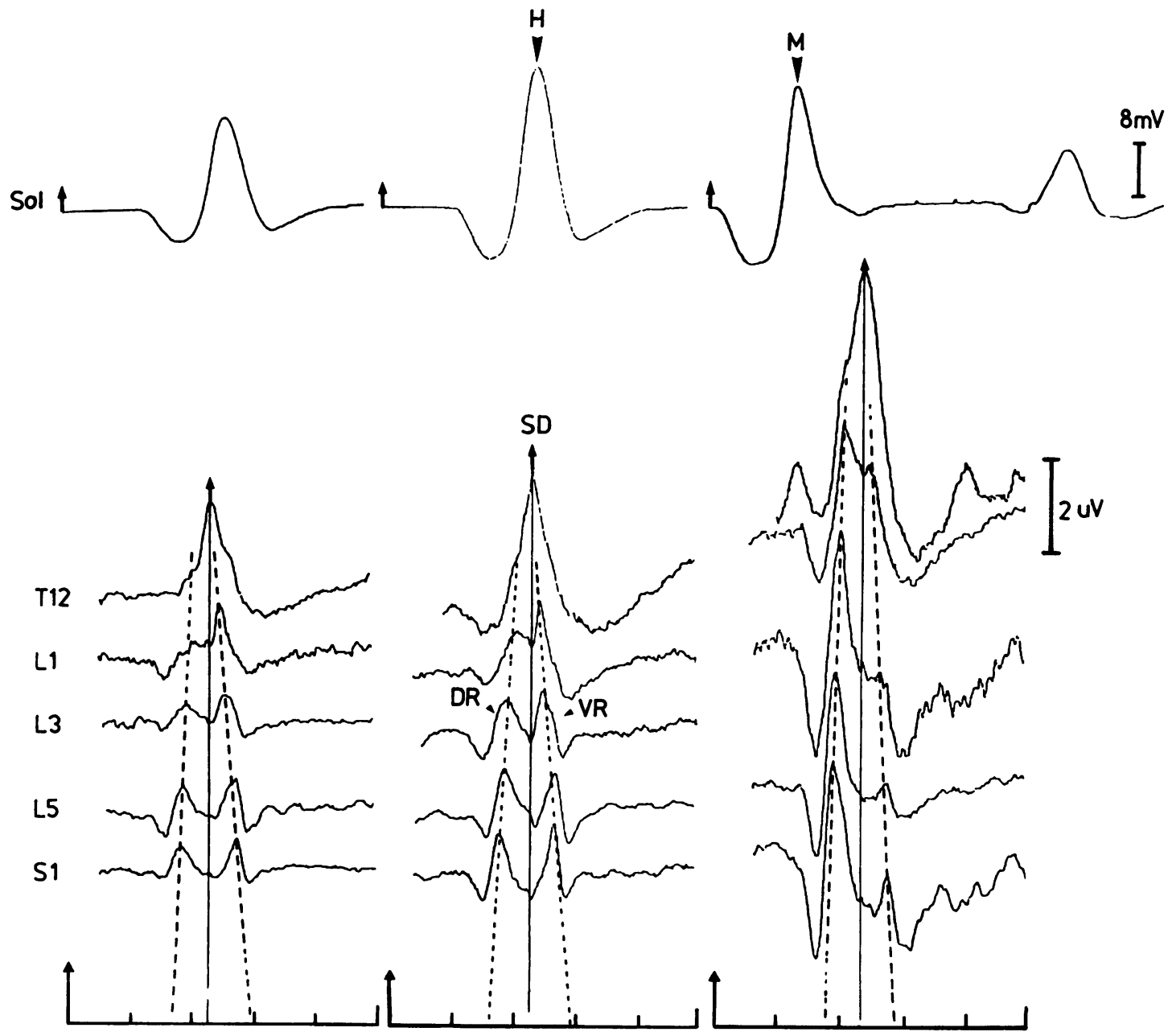

Fig 1 Surface recordings of activity over the spine at T12-S1 vertebral levels evoked by stimulation of the tibial nerve in the popliteal fossa at three different stimulus intensities. The upper traces show the recordings over the triceps surae muscle. The H-reflex response appears as the late wave and the direct muscle response ( $M$-wave) appears early in the third trace. (There is a delay from the stimulus to the beginning of the triceps-surae recordings $-20 \mathrm{~ms}$ for the left and middle panels and $5 \mathrm{~ms}$ for the last panel.) The triphasic SD (spinal cord dorsum, DR (dorsal root), VR (ventral root) waves are identified. The $D R$ and VR potentials are clearly travelling in opposite directions. All traces are the average of 128 responses. The calibration bar is $2 \mu v$ and the time scale is $5 \mathrm{~ms}$ per division. 
the six subjects when tibial and sural nerve responses were compared, stimuli of $0.2 \mathrm{~ms}$ duration were presented at a rate of $2 \mathrm{~Hz}$ with intensity sufficient to produce a muscle twitch (tibial) or three times sensory threshhold (sural nerve).

\section{Results}

I Spinal responses during posterior tibial nerve stimulation in the popliteal fossa

Well defined, reproducible spinal evoked potentials
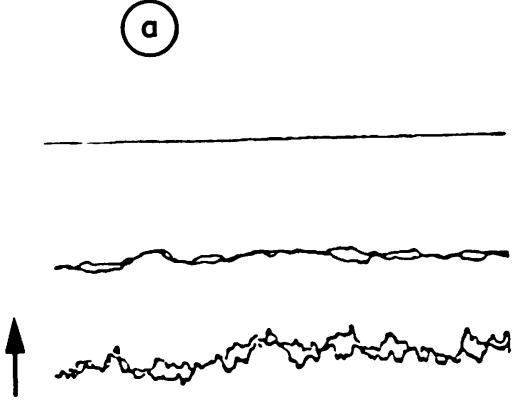

(b)
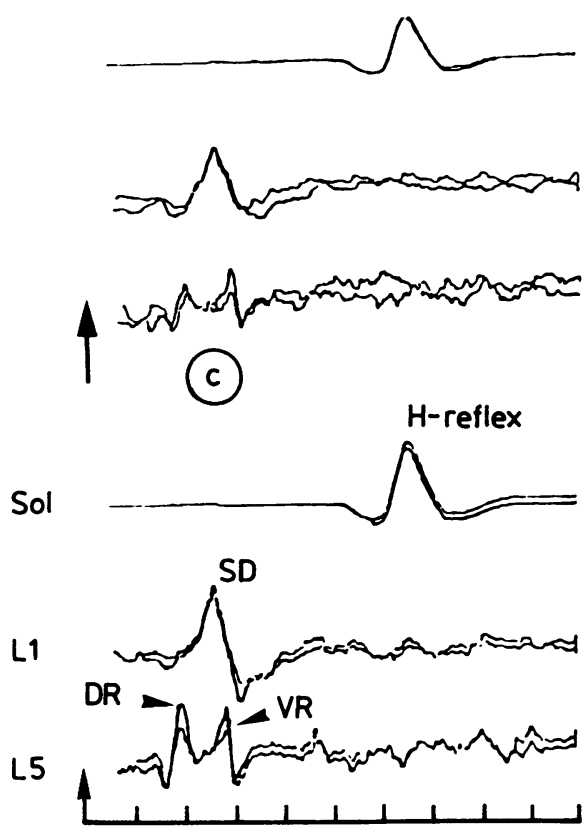

were obtained in all subjects. An analysis of the distribution of evoked responses within the lumbosacral region at three stimulus intensities one of which is maximal for the H-reflex, is given in fig 1 . Potentials were largest at the T12 spinous process, where they consisted of a triphasic wave (labelled SD-spinal cord dorsum) with a small initial positivity, a large negativity and following prolonged positive, potential. Progression in a caudal direction led to a noticeable difference in the evoked potentials. At these latter

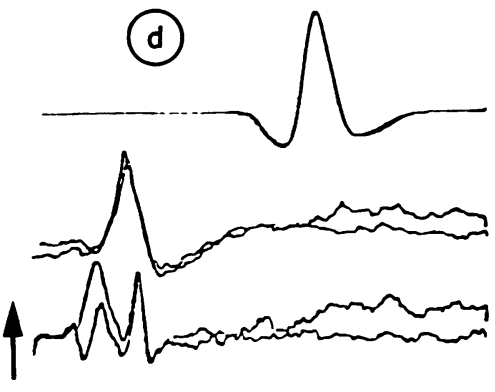

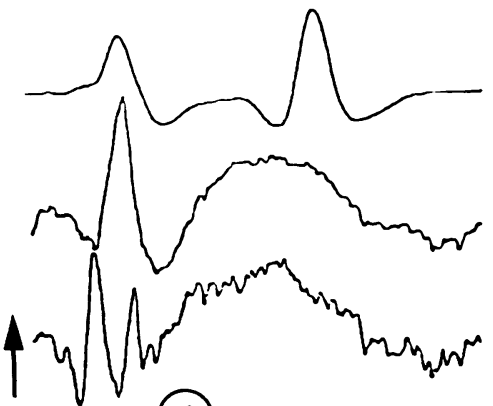

(d)

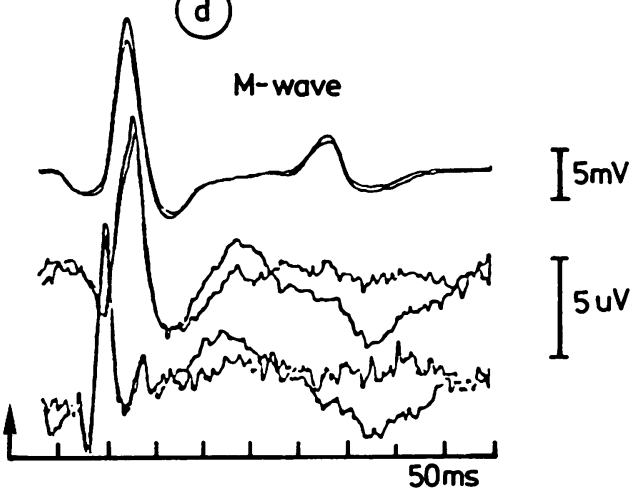

Fig 2 Spinal responses from $L 1$ and L5 electrodes and EMG responses from triceps-surae on stimulation of the posterior tibial nerve at the popliteal fossa with increasing stimulus strengths. At intensities subliminal to the production of an $H$-reflex, (a) $D R$ and $S D$ potentials are obtained but there is no VR potential. There is growth of all potentials $(D R, S D, V R)$ until there is a maximal H-reflex (b-d). With greater intensities (e-f) the M-wave appears, the H-reflex is suppressed. There is further growth of the $D R$ and $S D$ potentials but there is suppression of the VR potentials. All traces are the average of 256 responses and a repeat run is superimposed. 
Table 1 Latencies of potentials recorded over the spine (T12-S1) on stimulating the tibial nerve in the popliteal fossa

\begin{tabular}{llll}
\hline $\begin{array}{l}\text { Vertebral } \\
\text { Level }\end{array}$ & $\begin{array}{l}\text { DR } \\
\text { Latency } \\
\text { Mean }\end{array}$ & $\begin{array}{l}\text { SD } \\
\text { Latency } \\
\text { Mean }\end{array}$ & $\begin{array}{l}\text { VR } \\
\text { Latency }(M S) \\
\text { Mean }\end{array}$ \\
\hline T12 & & $12 \cdot 8$ & \\
L1 & 11.5 & & 13.6 \\
L3 & 11.1 & $14 \cdot 1$ \\
L5 & 10.6 & $14 \cdot 6$ \\
S1 & 9.7 & 14.9 \\
\hline
\end{tabular}

sites there was an initial positive negative-deflection of lower amplitude, appearing at shorter latencies (labelled DR-dorsal root), which was clearly separated from a later negative wave (labelled VR- ventral root).

Latencies to negative peaks were measured at all levels and are represented in table 1. These latencies were directly proportional to the distance between the stimulating and recording sites. The latencies of the dorsal root potential progressively increased in the rostral direction (mean S1: $9.7 \mathrm{~ms}$; mean L1: $11.5 \mathrm{~ms}$ ), whereas the ventral root potential progressively increased in the caudal direction (mean S1: $15.1 \mathrm{~ms}$; mean L1: $12.8 \mathrm{~ms}$ ). The mean latency for the spinal cord dorsum responses was $12 \cdot 8 \mathrm{~ms}$.

(a) Effect of stimulus intensity Effects of progressive increase in strength of nerve stimulation on the lumbar spinal potentials are illustrated in fig 2 . The H-reflex and direct motor responses (M-waves) are shown in EMG traces from the triceps surae muscle. When the stimulus was sub-threshhold for the $\mathrm{H}$ reflex a low amplitude dorsal root wave and spinal cord dorsum wave are often seen (fig $2 \mathrm{a}$ ). When the stimulus strength is increased above the threshold for the H-reflex, distinct dorsal root, spinal cord dorsum and ventral root potentials can be seen (fig $2 b$ ). Further increasing the strength of the stimulus (fig 2) leads to an increase in the amplitude of the dorsal root, spinal cord dorsum and ventral root potentials coincident with the increase in the amplitude of the $\mathrm{H}$-reflex. A further increase in the stimulus intensity, such that direct muscle response was produced (2e) led to a further increase in the dorsal root and spinal cord dorsum potentials but no change in the ventral root response.

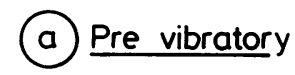

(b) vibratory
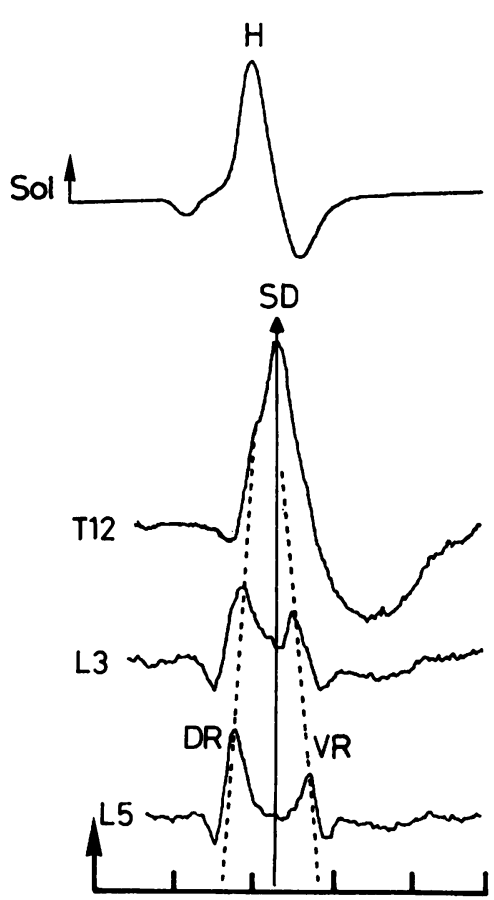
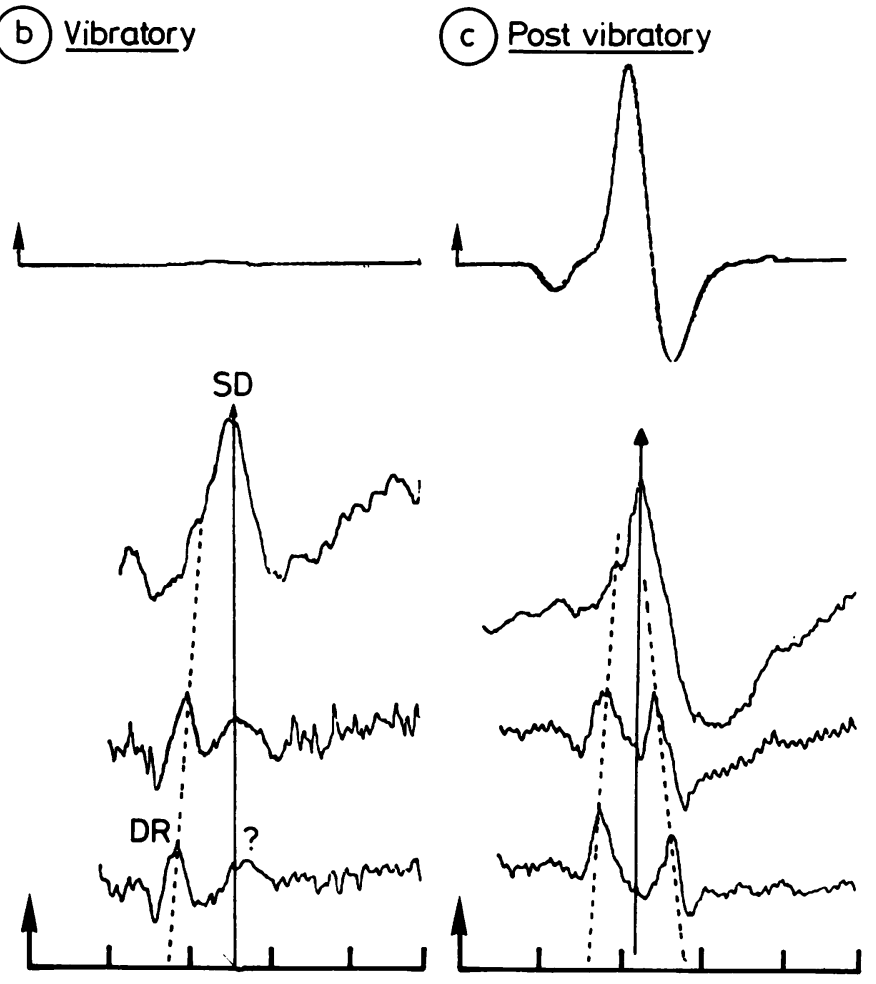

Fig 3 Spinal potentials recorded over the lumbar spine (T12-L5) to stimulation of the tibial nerve in the popliteal fossa. The upper traces show recordings over the triceps surae muscle (20 ms display delay). Vibration to the calf muscles leads to suppression of the H-reflex and the VR potential. There is no significant effect on the DR and SD responses. Each trace is the average of 256 responses. The time-scale is $5 \mathrm{~ms}$ per division. 
When a larger $\mathbf{M}$ response was produced, and the H-reflex was partially suppressed, maximal dorsal root and spinal cord dorsum responses were produced but the ventral root potential was reduced in amplitude (although not abolished). This experiment suggests a possible relationship between the dorsal root, spinal cord dorsum and ventral root response and $\mathrm{H}$-reflex amplitudes up until the development of the M-response.

(b) Responses to vibration Having found the aforementioned relationship between the lumbosacral potentials and the H-reflex, we tested, in two subjects, the effects of muscle vibration on the lumbosacral potentials obtained with tibial nerve stimulation (fig 3).

Vibration resulted in immediate suppression of the $\mathrm{H}$-reflex and the ventral root potential but there was little change in the afferent (dorsal root) potential or the spinal cord dorsum response (the slight reduction in amplitude of the dorsal root potential may have been due to the reduced signal to noise ratio with vibration). The ventral root potential was replaced by a low amplitude wave which was of longer duration, and did not show the same latency change between L3 and L5 electrodes.

(c) Responses to high frequency stimulation Low intensity stimulation at a rate of $0.5 \mathrm{~Hz}$ produced a maximal $\mathrm{H}$-reflex and well-defined dorsal root, spinal cord dorsum and ventral root potentials. Stimulation at the same stimulus intensity at a rate of $4 \mathrm{~Hz}$ suppressed the H-reflex and ventral root potentials but produced no significant change in the configuration, amplitude or latency of the dorsal root or spinal cord dorsum responses (fig 4).

\section{Responses to tibial and sural nerve stimulation at the ankle}

When the tibial nerve was stimulated at the ankle (at threshhold for the direct motor response to abductor hallucis), spinal records from T12, L1, L3, L5, S1 showed three distinct negative peaks (fig $5 \mathrm{a}$ ). Over the cord dorsum (T12-L1) a triphasic potential was seen (mean latency of $20.6 \mathrm{~ms}$ ) which was similar to the spinal cord dorsum potential obtained when the tibial nerve was stimulated in the popliteal fossa. At S1-L3 levels a double peaked response was observed. The latency of the first peak progressively increased in the rostral direction, while latency of the second peak remained constant at the same latency as the potential recorded over the cord dorsum (table 2). When the intensity of the stimulus was increased such that a maximal $\mathrm{M}$ response was produced (fig $5 \mathrm{~b}$ ) there was an increase in the amplitude of all the potentials, including the second negative peak (as compared with the ventral root response with stimulation at the knee,
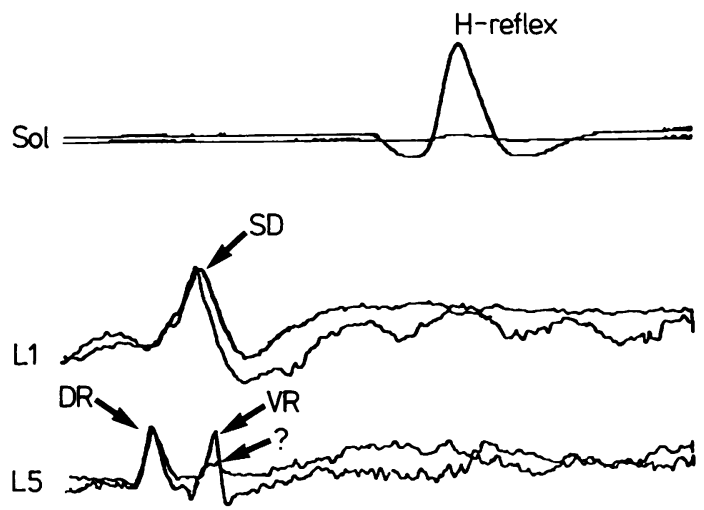

$100 \mathrm{~ms}$

Fig 4 Spinal potentials recorded over LI and LS to stimulation of the tibial nerve in the popliteal fossa at different frequencies $(1 / 2 \mathrm{sec}$ and $4 / \mathrm{sec})$. The upper traces are recording the $H$-reflex over the triceps surae muscle (20 $m s$ display delay). At $4 / \mathrm{s}$ there is suppression of the $H$-reflex and VR potential with no effect on the $D R$ or $S D$ potentials. Each trace is the average of 256 responses. The time scale is $5 \mathrm{~ms}$ per division.

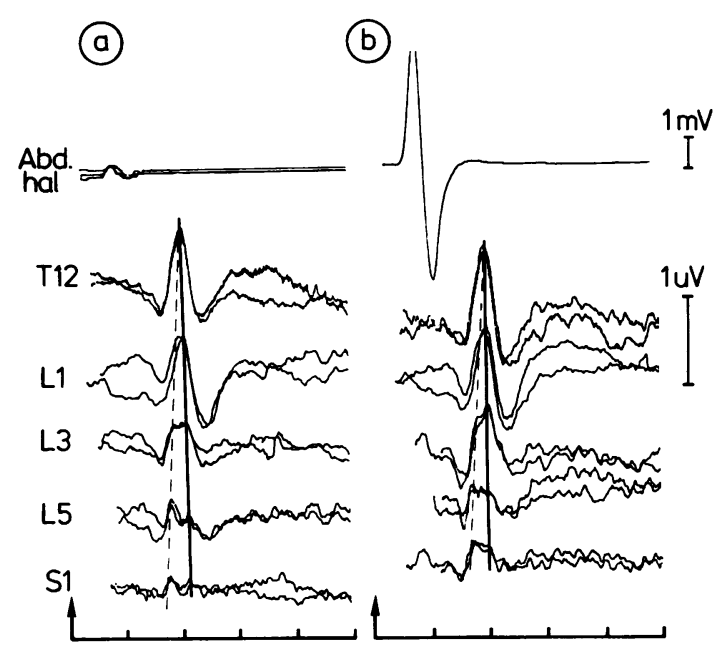

Fig 5 ( $a$ and $b$ ) Spinal potentials recorded over the T12-S1 vertebral levels to stimulation of the posterior tibial nerve at the ankle. The upper traces are recording motor activity over abductor hallicus muscle. The traces on the left (a) one recorded at submaximal intensities. Two waves can be identified: a travelling wave (dotted line) and a standing wave (filled in line). When the stimulus intensity is increased to produce a maximal motor response from abductor hallucis all potentials became larger. Each trace is the average of 256 responses. The time scale is $10 \mathrm{~ms}$ per division. 


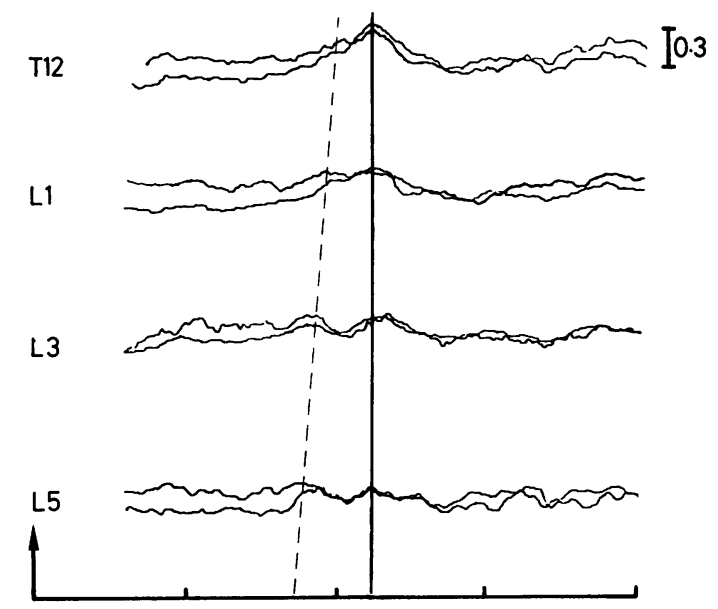

Fig 6 Spinal potentials recorded over T12-L5 vertebral levels to stimulation of the sural nerve at the ankle. Two waves can be identified: a wave travelling rostrally (dotted line) and a standing wave (filled in line). Each trace is the average of 512 responses. The time scale is $10 \mathrm{~ms}$ per division.

which was suppressed at stimulus intensities producing maximal $\mathbf{M}$ response).

In the same patients the sural nerve (a purely cutaneous nerve) was stimulated over the lateral aspect of

\section{Sural (ankle) SEP-left}

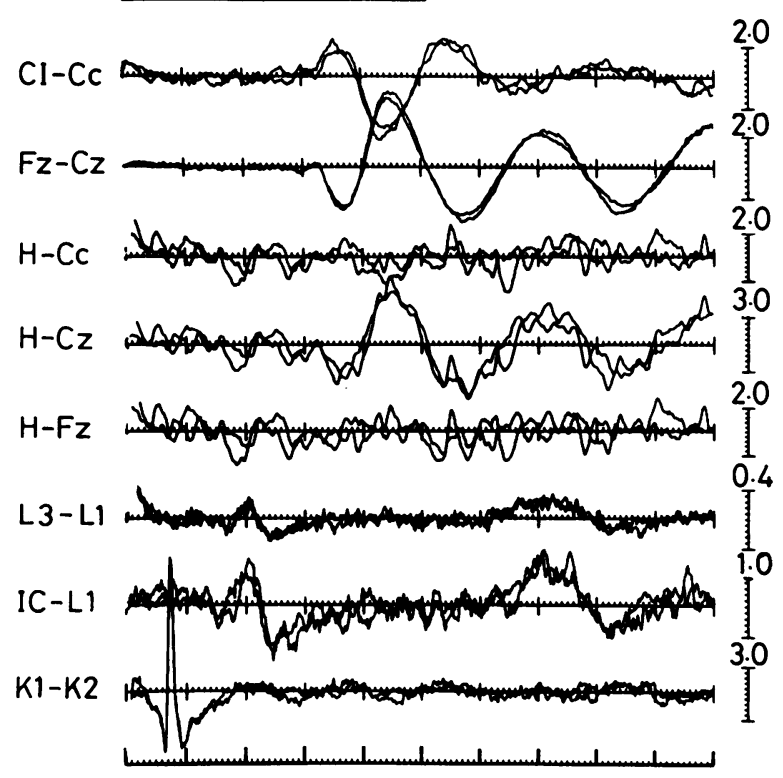

Table 2 Latencies of potentials recorded over the spine (T12-S1) on stimulating the tibial nerve at the ankle (T) and sural nerve at the ankle $(S)$

\begin{tabular}{|c|c|c|c|c|c|c|}
\hline \multirow[b]{2}{*}{$\begin{array}{l}\text { Nerve } \\
\text { Vertebrae }\end{array}$} & \multicolumn{2}{|c|}{$\begin{array}{l}\text { DR } \\
\text { Latency (MS) } \\
\text { Mean }\end{array}$} & \multicolumn{2}{|c|}{$\begin{array}{l}S D \\
\text { Latency (MS) } \\
\text { Mean }\end{array}$} & \multicolumn{2}{|c|}{$\begin{array}{l}N_{2} \\
\text { Latency (MS) } \\
\text { Mean }\end{array}$} \\
\hline & $T$ & $S$ & $T$ & $S$ & $T$ & $S$ \\
\hline $\begin{array}{l}\text { T12 } \\
\text { L1 } \\
\text { L3 } \\
\text { L5 } \\
\text { S1 }\end{array}$ & $\begin{array}{l}20.0 \\
19.0 \\
18.4 \\
18.0\end{array}$ & $\begin{array}{l}19.4 \\
18.9 \\
18.3 \\
18.2\end{array}$ & $21 \cdot 0$ & $22 \cdot 1$ & $\begin{array}{l}21 \cdot 0 \\
21 \cdot 0 \\
21 \cdot 2 \\
21 \cdot 1\end{array}$ & $\begin{array}{l}22 \cdot 1 \\
22 \cdot 1 \\
22 \cdot 3 \\
22 \cdot 0\end{array}$ \\
\hline
\end{tabular}

the ankle under the lateral malleolus. Three distinct negative peaks were again noted at similar levels of those obtained on tibial nerve stimulation (ankle). These responses were of significantly lower amplitude and increased duration (fig 6) and the latency of the spinal cord dorsum potential was marginally longer than that obtained by stimulating the tibial nerve at the ankle. The latency of the first negative peak had a similar increase in latency at more rostral recordings sites and the second negative peak maintained the same latency at all levels which was identical to that of the response obtained over the cord dorsum (table 2).

Fig 7 Scalp and spinal and popliteal fossa $(K 1-K 2)$ potentials recorded to stimulation of the sural nerve and tibial nerve at the ankle. The amplitude over the cord dorsum was at least 5 times greater on tibial nerve stimulation than on sural nerve stimulation whereas over the scalp this approximated 2:1. Each trace is an average of 512 responses for the tibial and 1024 responses for the sural. 
In a further six subjects, evoked potentials with tibial (ankle) and sural nerve stimulation were also recorded over the scalp and in the popliteal fossa (fig 7). The amplitude over the cord dorsum was at least five times greater with tibial nerve stimulation (mean $-1.4 \mu \mathrm{V}$ ) than with sural nerve stimulation (mean $-0.3 \mu \mathrm{V}$ ) whereas, regarding scalp responses, there was only a 2:1 difference in amplitude, the sural evoked N/P37 scalp response being smaller. In the popliteal fossa the tibial response was two to three times the size of the sural response.

\section{Discussion}

Magladery et $a l^{1}$ in a now classical investigation describes electrical activity in human lumbosacral roots and thoracolumbar cord produced by stimulation of various peripheral nerves in the lower limbs. These studies utilised invasive techniques (insertion of steel needles into the lumbar subarachnoid space) and consequently their clinical applications were limited. With the advent of signal averaging, low-amplitude lumbar potentials have been recorded non-invasively from the skin surface. ${ }^{7}$ Subsequently a number of authors ${ }^{2-6}$ used surface recording techniques to reexamine the origin of the major components of the lumbosacral evoked responses and their relationship to the monosynaptic reflex. Their findings were in conflict with Magladery's original work and with each other. With stimulation of the tibial nerve in the popliteal fossa all studies have found two distinct types of potentials. When recording at the spinous process level of T12 the evoked potential is a smooth triphasic wave with an initial sharp positivity followed by a large negative wave and a long lasting positive deflection. This wave (called the spinal cord dorsum response in the present study) has been called the S-wave (Magladery et al, ${ }^{1}$ Ratto et $a l^{3}$ ) and Nwave (Delbeke et $a l^{2}$ ). At levels below L1 a double peaked response is obtained with a dominant early negative wave. The first negativity (dorsal root in the present study) has been called the R-wave (Magladery et $a l^{1}$ and the second negativity (ventral root in the present study) has been called the A-wave (Magladery et $\left.a l^{1}\right)$.

The dorsal root wave appears to be produced by action potentials conducted in sensory fibres which are running in the dorsal roots. This conclusion may be made from the following findings. The more rostral the recording site, the shorter the interval between the dorsal root and ventral root deflections (fig 1 and table 1) which must therefore indicate activity moving in opposite directions in neural pathways caudal to the cord. The progressive increase in latency of the dorsal root wave at more rostral recording sites and the progressive increase in its amplitude with greater stimulus intensities (fig 2) suggests it represents afferent impulses in dorsal roots. Furthermore high-frequency stimulation and vibration, which are thought to produce presynaptic inhibition of motoneurons, ${ }^{8-10}$ had no effect on the dorsal root potential even though they suppressed the ventral root response (fig $3 \& 4$ ).

Dorsal root activity is unlikely to be antidromic conduction up alpha motor axons because: (1) dorsal root potentials are clearly present well below motor threshhold when only the large diameter sensory afferents would be stimulated and (2) conduction velocity between $\mathrm{S} 1$ and $\mathrm{L} 1(83 \mathrm{~m} / \mathrm{s})$ is faster $(10-20 \%)$ than one would expect using indirect calculations of motor velocity. ${ }^{11}$ These findings are in agreement with those of Magladery and subsequent authors. However, unlike Magladery, we initially recorded the dorsal root potential without the ventral root potential. This is not surprising since in cat it has been estimated that to discharge motoneurons, impulses in about 50-100 Ia sensory afferents must reach the motoneuron membrane synchronously. ${ }^{12}$

Furthermore, in man it has been estimated by indirect methods that about 60 unitary Ia EPSPs are necessary to depolarise the motoneuronal membrane to threshhold and generate impulses in soleus motoneurons. ${ }^{13}$ In a human soleus muscle, the number of spindles has been estimated to be about $300,{ }^{14}$ thus approximately $20 \%$ or more of the population of Ia afferents must be excited to generate impulses in soleus motoneurons. Thus it would not be surprising to record a synchronous afferent volley of low amplitude before the excitation of the motoneuron and the resulting development of the ventral root potential.

The ventral root wave (Magladery's A-wave) most likely represents reflex outflow in motor axons through the ventral roots as suggested by the following observations. First, its increased latency at successively more caudal recording sites is in keeping with this interpretation and would suggest activity in fibres conducting in the opposite direction to the dorsal root potential. The ventral root response first appears simultaneously with the H-reflex and is greatest in amplitude when the $\mathrm{H}$-reflex is maximal. As the stimulus intensity is increased further and an M-response appears there is progressive reduction in amplitude of both the ventral root response and the H-reflex. The decreased amplitude would be consistent with occlusion of the distalward conducted reflex discharge by antidromic impulses in motor axons proximal to the recording site.

Further evidence for this contention is provided by studying the effects of high frequency stimulation and vibration on the ventral root response. With a stimulation frequency of $4 \mathrm{~Hz}$ both the $\mathrm{H}$-reflex and the 
ventral root potential are suppressed (fig 3 ) with no significant effect on the dorsal root or spinal cord dorsum potential. This would suggest a reduction in central excitability of the motor neuron pool and demonstrates a direct relationship between the generation of the ventral root potential and the presence of an H-reflex. Vibration applied to the soleus muscle suppressed the H-reflex as has been described by others. ${ }^{38910}$ This was associated with suppression of the ventral root potential but no significant change in dorsal root or spinal cord dorsum potentials (fig $3 b$ ). When vibration ceased, both the H-reflex and the ventral root potential return to normal. These features suggest that suppression of the H-reflex is due to central inhibition rather than occlusion of Ia afferent fibres by vibration-induced activity. This is consistent with the work of Gillies et al ${ }^{15}$ who found that in the cat during muscle vibration, a dorsal root potential and primary afferent depolarisation of Ia afferent terminals could be demonstrated but the reflex activation of the motoneuron was suppressed.

Some of the second negativity recorded over the spine caudally (L3-S1) may be due to electrotonic conduction of the spinal cord dorsum potential from the termination of the spinal cord as is suggested by the fact that (a) it does not completely disappear when the H-reflex is suppressed by strong stimuli and vibration and (b) the latency to peak of the second

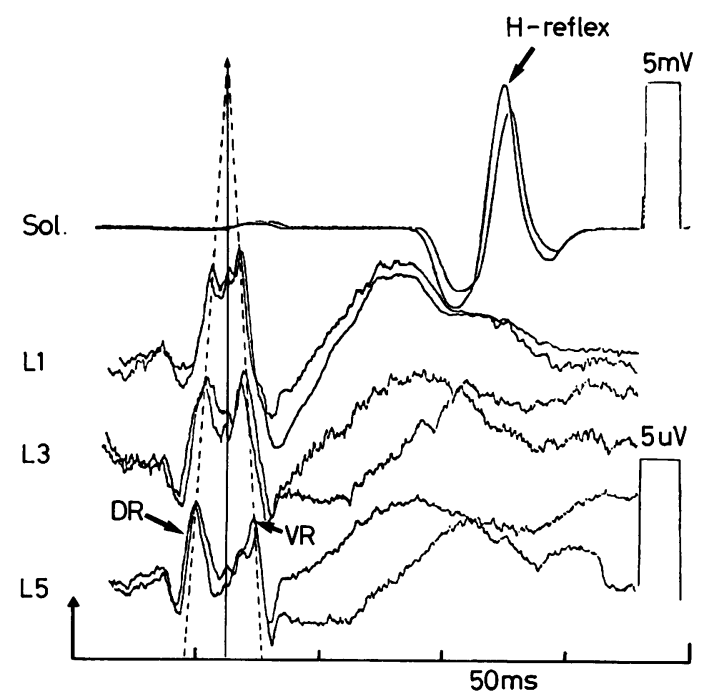

Fig 8 Spinal potentials recorded over the L1-L5 vertebral levels to stimulation of the posterior tibial nerve at the popliteal fossa. The upper traces represent motor activity over the triceps surae muscle ( $H$ reflex, $M$ response). Two waves can be identified ( $D R, V R)$ travelling in opposite directions. In addition there is standing wave (filled in line which may represent electrotonic conduction of the $S D$ potential). Each trace is the average of 256 responses. negative wave in these situations corresponds to that of the spinal cord dorsum potential (fig $3 \mathrm{~b}$ ). This wave is not likely to be due to antidromic motor activity since the latency does not progressively increase in the rostral direction. In the occasional subject this standing wave could be detected as a discrete negativity separate from the dorsal root and ventral root potential (fig 8).

These findings are in general agreement with the early studies of Magladery and those of Ratto et $a^{3}$ and extend those of Delbeke $e t a l^{2}$ and Dimitrijevic et $a l^{4}$ but are in disagreement with those of El-Negamy and Sedgwick ${ }^{5}$ and Phillips and Daube. ${ }^{6}$ These latter authors suggested there was no relationship between the spinal responses and the $\mathrm{H}$-reflex. This was based on the finding of a second negative peak when stimulating the tibial nerve at the ankle (a mixed nerve supplying foot muscles without a discernable $\mathrm{H}$ reflex), and the sural nerve (a purely cutaneous nerve), which they suggested could not be due to reflex activity in ventral roots. In our study stimulation of the tibial or sural nerve at the ankle produced two negative waves one of which was a travelling wave similar to the dorsal root potential and the second a standing negativity which appeared to be volume-conducted negativity generated by the caudal spinal cord. This negativity had a latency similar to the spinal cord dorsum potential, became larger as the direct muscle response increased in size and was clearly not associated with an $\mathrm{H}$-reflex. These findings correlate well with studies with stimulation of sciatic nerve of cat and monkey ${ }^{16-20}$ and with those of Phillips and Daube ${ }^{6}$; however, these latter authors failed to distinguish between this standing negativity and the travelling ventral root potential found on stimulation of the posterior tibial nerve in the popliteal fossa which appears to be a ventral root potential associated with the $\mathrm{H}$-reflex.

With liminal stimuli (which also evoked the first detectable dorsal root potential), a small negative deflection followed by a prolonged positivity was noted over the rostral spinal cord (spinal cord dorsum). This potential was similar to the dorsal spinal action potentials first described in cats by Gasser and Graham ${ }^{21}$ and designated by them "the intermediary potential". Similar triphasic waves have been obtained in humans by intra-thecal, ${ }^{12223}$ epidural $^{24-26}$ and surface recordings. ${ }^{2-727}$ Shimizu et $a l^{24}$ and Shimoji et $a l^{26}$ suggested the P1 N1 and P2 components of the triphasic spinal potential reflect activity in the intramedullary portion of the afferent axon, interneuronal activities and primary afferent depolarisation respectively. Similar studies in animals have suggested that these are internuncial spinal potentials related to synaptic activity of afferent fibres with dendrites of dorsal horn neurons running 
dorsally from the perikaryon and perpendicular to the surface of the cord. ${ }^{28}$ The latter positivity is consistent with depolarisation of terminals of primary afferents responsible for presynaptic inhibition. ${ }^{29} 30$ A synchronous volley in dorsal root fibres within the cord may contribute to the spinal cord dorsum negativity and the notch on the upstroke of this negativity termed N1 by Austin and McCouch ${ }^{31}$ and Delbeke $e t$ $a l^{2}$ which was sometimes seen in our study (fig 2). Although there is some agreement concerning spinal mechanisms that generate the spinal cord dorsum potential there is considerable controversy relating to the nature of the afferent fibres that synapse in the dorsal horn.

Most workers believe that both the negative and positive cord potentials are due predominantly to activity propagated in cutaneous afferent fibres; ${ }^{12212731-33}$ however, a number of workers have suggested that the peripheral nerve fibres that mediate the surface-recorded spinal potential are primarily muscle afferents. ${ }^{10161734-36}$ Our data suggest a significant contribution from muscle afferents to the spinal cord dorsum potential. The amplitude of the spinal cord dorsum potential with sural nerve stimulation was considerably smaller than that produced by posterior tibial nerve stimulation at the ankle (mean ratio 1:5) and was often of longer duration. In scalp recordings the amplitude ratio of the earliest cortical potential (N/P37) was usually more favourable for the sural nerve (1:2 mean). If cutaneous afferents in both nerves produced most or all the post-synaptic cord potentials and continued rostrally through the dorsal column-lemniscal system to reach cortex, the amplitude ratio should, at least as a first approximation, be dependent on the relative numbers of cutaneous afferents in the tibial and sural nerves and would be the same at spinal and cortical levels.

Our findings suggest that the mixed nerve (posterior tibial at the ankle) contains afferent fibres involved in synaptic activity which are not found in cutaneous nerves. This difference may relate to the presence of muscle afferents in the mixed nerve and would be consistent with the heavy concentration of collaterally inverted terminals of muscle afferents with synaptic connections at the spinal level which would produce a considerable expansion of electrically active tissue. ${ }^{35} 38$

These findings have been confirmed in studies on cat that compared spinal potentials produced by cutaneous nerve (sural, superficial peroneal) versus muscle nerve (nerve to medial gastrocnemius) afferent volleys. ${ }^{163537}$

On the basis of latency and distribution, we conclude the potentials generated in the lumbosacral area are of afferent, spinal and efferent origin. When the tibial nerve is stimulated in the popliteal fossa, three negative peaks are recorded which arise from activity in dorsal roots travelling rostrally, dorsal horn of the spinal cord (standing) and ventral roots travelling caudally. The ventral root potential represents the reflex volley in ventral roots responsible for the generation of $\mathrm{H}$-reflex. In contrast, when the tibial nerve at the ankle and the sural nerves are stimulated and do not produce an H-reflex, two negative peaks are recorded. The first travels in a rostal direction and is generated by the dorsal roots whereas the second negativity is a standing wave generated in the dorsal horn of the caudal spinal cord. In addition, our data suggest that the peripheral nerve fibres which are involved in generating the surface recorded spinal potential with mixed nerve stimulation are primarily muscle afferents. These conclusions have important implications in the applications of this technique to the assessment of pathology of dorsal and ventral roots which are relatively inaccessible by conventional neurophysiological techniques.

\section{References}

1 Magladery JN, Porter WE, Park AM, Teasdall R. Electrophysiological studies of nerve and reflex activity in normal man. IV. The two-neuron reflex and identification of certain action potentials from spinal roots and cord. Bull Johns Hopkins Hos 1957;88:499-519.

2 Delbeke J, McComas AJ, Kopec SJ. Analysis of evoked lumbosacral potentials in man. J Neurol Neurosurg Psychiatry 1978;41:293-302.

3 Ratto S, Abbruzzese M, Abbruzzese G, Favale E. Surface Recording of the Spinal Ventral Root Discharge in Man. Brain 1983;106:897-909.

4 Dimitrijevic MR, Larsson LE, Lehmkuhl D, Sherwood A. Evoked spinal cord and nerve root potentials in humans using a non-invasive recording technique. Electroencephalogr Clin Neurophysiol 1978;45:331-40.

5 El-Negamy E, Sedgwick EM. Properties of a spinal somatosensory evoked potentials recorded in man. $J$ Neurol Neurosurg Psychiatry 1978;41:762-8.

6 Phillips LH, Daube JR. Lumbosacral spinal evoked potentials in humans. Neurology 1980;30:1175-83.

7 Cracco RQ. Spinal evoked response: peripheral nerve stimulation in man. Electroencephalogr Clin Neurophysiol 1973;35:379-86.

8 Lance JW, Neilson PD, Tassinari DA. Suppression of the HReflex by peripheral vibration. Proc Austr Ass Neurol 1968;5:45-9.

9 Rushworth G, Young RR. The effects of vibration on tonic and phasic reflexes in man. J Physiol (Lond) 1966;185:63-4.

10 Delwaide PJ. Approch de la physiopathologie de la spasticité: réflexe de Hoffmann et vibrations appliquées sur le tendon d'Achille. Rev Neurol (Paris) 1969;121:72-4.

11 Diamantopoulos E, Gassel MM. Electrically induced monosynaptic reflexes in man. $J$ Neurol Neurosurg Psychiatry 1965;28:496-502.

12 Mendell LM, Henneman E. Terminals of single Ia fibers: location density and distribution within a pool of 300 homonymous motoneurons. J Neurophys 1971;34:171-87.

13 McComas AJ, Mirsky M, Struppler A, Vellho F. Indirect estimation of EPSPs in human soleus motoneurons. $J$ Physiol (Lond) 1979;287:P14-5

14 McComas AJ. Neuromuscular Function and Disorders, Butter- 
worths: London, 1977:307-10.

15 Gillies D, Lance LW, Neilson PD, Tassinari CA. Presynaptic inhibition of the monosynaptic reflex by vibration. $J$ Physiol (Lond) 1969;205:329-39.

16 Sarnowski RJ, Cracco RQ, Vogel HB, et al. Spinal evoked responses in the cat. $J$ Neurosurg 1975;43:239-36.

17 Cracco RQ, Evans B. Spinal evoked potentials in the cat: effects of asphyxia, strychnine, cord section and compression. Electroencephalogr Clin Neurophysiol 1978;44:187-201.

18 Deecke L, Tator $\mathrm{CH}$. Neurophysiological assessment of afferent and efferent conduction in injured spinal cord of monkeys. $J$ Neurosurg 1973;39:65-74.

19 Gelfan S, Tarlov IM. Physiology of the spinal cord, nerve root and peripheral nerve compression. $\mathrm{Am} \quad J$ Physiol 1956;185:217-29.

20 Feldman MH. Cracco RQ, Farmer P, Mount F. Spinal evoked potentials in monkey. Ann Neurol 1980;7:238-44.

21 Gasser HS, Graham HI. Potentials produced in the spinal cord by stimulation of dorsal roots. Am J Physiol 1933;103:303-20.

22 Ertekin C. Studies on the human evoked electrospinograms. I The origin of the segmental evoked potentials. Acta Neurol Scand 1976;53:3-20.

23 Ertekin C. Studies on the human evoked electrospinograms. II The conduction velocity along the dorsal funiculus. Acta Neurol Scand 1976;53:21-38.

24 Shimizu H, Shimoji K. Maruyma Y, et al. Slow cord dorsum potentials elicited by descending volleys in man. $J$ Neurol Neurosurg Psychiatry 1979;42:242-6.

25 Shimoji K, Kano T, Higashi H. et al. Evoked spinal electrograms in man. $J$ App Physiol 1972;33:468-71.

26 Shimoji K, Kano T, Higashi H. Epidural recording of spinal electrogram in man. Electroencephalogr Clin Neurophysiol 1971;30:236-9.
27 Jones SJ, Small DG. Spinal and subcortical evoked potentials following stimulation of the posterior tibial nerve in man. Electroencephalogr Clin Neurophysiol 1978;44:299-306.

28 Scheibel ME, Scheibel AB. Terminal axonal pattern in cat spinal cord. II. The dorsal horn. Brain Res 1968;9:32-58.

29 Wall PD. Excitability changes in afferent fibre terminations and their relation to slow potentials. J Physiol (Lond) 1958; 142:1-21

30 Eccles JC, Kostyuk PG, Schmidt RF. Central pathways responsible for depolarization of primary afferent fibres. $J$ Physiol (Lond) 1961;161:237-57.

31 Austin GM, McCouch GP. Presynaptic component of intermediatry cord potential. J Neurophys 1955;18:441-51.

32 Hughes J, Glasser HS. Some properties of the cord potentials evoked by a single afferent volley. Am J Physiol 1934; 108:303-20.

33 Bernhard CG. The spinal cord potentials in leads from the cord dorsum in relation to the peripheral source of afferent stimulation. Acta Physiol Scand 1953;Suppl 106, 29:1-29.

34 Lloyd DPC, McIntyre AK. On the origins of dorsal root potentials. J Gen Physiol 1949;32:409-43.

35 Lloyd DPC, McIntyre AK. Dorsal column conduction of group I. Muscle afferent impulses and their relay through Clarkes column. J Neurophysiol 1959;13:39-54.

36 Happel LT, Leblanc HJ, Kline DG. Spinal cord potential evoked by peripheral nerve stimulation. Electroencephalogr Clin Neurophysiol 1975;38:349-54.

37 Willis WD, Weir MA, Skinner RD, Bryan RN. Differential distribution of spinal cord field potentials. Exp Brain Res 1973;17:169-76.

38 DeMolina AF, Gray JAB. Activity in the dorsal spinal grey matter after stimulation of cutaneous nerves. $J$ Physiol (Lond) $1957 ; 137: 126-40$ 